\title{
Value Management Integration for Whole Life Cycle: Post COVID-19 Strategy for the UK Construction Industry
}

\author{
Kieran Bennett and Mohammad Mayouf *D \\ School of Engineering and the Built Environment, Birmingham B4 7XG, UK; Kieran.Bennett@mail.bcu.ac.uk \\ * Correspondence: Mohammad.Mayouf@bcu.ac.uk
}

Citation: Bennett, K.; Mayouf, M. Value Management Integration for Whole Life Cycle: Post COVID-19 Strategy for the UK Construction Industry. Sustainability 2021, 13, 9274. https://doi.org/10.3390/su13169274

Academic Editors: Nikos

A. Salingaros, Michail Kagioglou and Saeed Talebi

Received: 24 May 2021

Accepted: 13 August 2021

Published: 18 August 2021

Publisher's Note: MDPI stays neutral with regard to jurisdictional claims in published maps and institutional affiliations.

Copyright: (C) 2021 by the authors. Licensee MDPI, Basel, Switzerland. This article is an open access article distributed under the terms and conditions of the Creative Commons Attribution (CC BY) license (https:// creativecommons.org/licenses/by/ $4.0 /)$.

\begin{abstract}
Value management (VM) and its integration in the whole life cycle (WLC) have become huge concepts for construction projects to provide additional value of an asset for the end user or client. However, the role of VM and its integration as part of the WLC in a construction project remain reactive, and highly impacted by nature of the project, and this has become more challenging with the epidemic impact of COVID-19. This research aims to investigate the mechanisms that delivers value management as part of the "re-invent" strategy proposed by the Construction Leadership Council in the UK government to improve WLC for buildings. In addition to existing secondary data from the literature, primary data were attained using a focus group with six quantity surveyors from different cost consultancies in the UK to gather qualitative evidence using their experiences, perceptions, and key challenges they face when integrating VM. Findings revealed that value management is primarily being used as a cost-cutting tool, the majority of quantity surveyors lack knowledge of what it encompasses, hence the industry needs a more proactive strategy towards it. Analysis revealed that value management is primarily implemented as a cost-cutting solution, key stakeholders (e.g., facility managers) need to be integrated, and there is no standardised process to incorporate value management in projects. The study proposes a four-dimensional (governance and policies, sustainability, industry's best practice, and innovation and technology) strategy to facilitate more holistic considerations of value management post COVID-19. Future work looks into evaluating the strategy proposed while acknowledging different procurement routes.
\end{abstract}

Keywords: value management; whole life cycle; strategy; COVID-19

\section{Introduction}

In a construction project, incorporating value management has continually been gaining importance and significance since the 1980s, with a balanced focus as a cost-cutting tool and on improving value for the overall project [1]. The origins of value management were first developed during World War II in America where materials became increasingly harder to attain; consequently, alternative materials which held the same functional ability were substituted [2]. Jaapar [3] defines value management as "a multi-disciplinary, team orientated, structured, analytical process and systematic analysis of function which seeks best value via the design and construction process to meet the clients perceived needs". Construction projects have evolved and adapted over the years and it is paramount that stakeholders identify their perceived values at the earliest stages [4]. It can be stated that value management is an influential mechanism to the success of a construction project, as it helps to deliver management of planning, design, and performance across the whole life cycle of a construction project [5]. On the one hand, considerations toward value management relies on understanding the synergy between different project requirements, and on the other hand, it requires an adequate identification of the most impactful stakeholders to maximise value for a project [6]. Reflecting on efforts by research and practice, it is recognised that value management and whole life cycle (WLC) are interconnected [7]. This is reasoned by the fact that value management is about providing informed decisions that 
support better value creation for different stakeholders and how this applies across the whole life cycle of a building [8]. In fact, success of a construction project life cycle is associated with value management through the entire supply chain, starting with extraction and supply of raw materials, composition and manufacturing of different building components, and the longevity of these components during building occupancy and usage. As part of WLC considerations, value management can be recognised as a major element, as its impact goes beyond design and construction to actually impact performance of the building on the long term $[9,10]$. Simultaneously with the previous, environmental (e.g., use of waste-free or sustainable materials) and social (e.g., value for occupants) considerations are equally important as part of value management and play a major role in the whole life cycle of an asset.

Across all industries, the epidemic impact of COVID-19 can be perceived as major and perhaps a game-changer as it shifted many of the conventionally applied processes. In the construction sector, the impact of COVID-19 was mainly mirrored through its impact on health and safety and how it can impact on-site operations, occupational health and safety, and unforeseen risks [11]. With the disruption of COVID-19, many construction projects have started to deploy lean processes that support an efficient supply chain with effective cost management [12]. The impact of COVID-19, beyond additional health and safety restrictions, has shifted many of the processes to being executed remotely, hence boosting the need to deploy digital solutions and techniques to support different aspects across the life cycle of a project. This implies the need to look at the entire supply chain in a construction project to explore efficient and effective mechanisms that support all stakeholders across the whole life cycle. In that respect, accountancy toward value management in a construction project remains one of the major priorities for construction projects and its value goes beyond cost cutting to actually validate how it impacts the whole life cycle. With the extensive existing knowledge on value engineering/management, research and practice continue to refine and innovate different mechanisms that can ensure holistic consideration of different stakeholders' needs and requirements [13]. Stakeholders may have different aspirations within a construction project, such as boosting their sustainability reputation or enhancing profitability, but to maximise project value requires a great level of cohesiveness and collaboration [14]. As Wandahl [15] outlines in his research, value is perceived in many ways by different stakeholders and disciplines, thus the nature of value management is complex and the level or amount implemented to each project is unique.

With the epidemic impact of COVID-19, it is expected that more challenges are imposed on "what-to-consider-first" when it comes to value management, and how it can be improved across the whole life cycle. The existence of digitalised processes such as Building Information Modelling (BIM) has enabled further capabilities of adding value to construction projects [16] as it supports informing planning, design, and construction stages of a project $[17,18]$. In fact, the use of common data environments has allowed for a more collaborative work ethos and can significantly reduce costs and material quantities through clash detections [19]. Although the integration of different stakeholders through digitalisation provided more potential for informed decisions about whole life cycle of a construction project, its impact on improving mechanisms and practices toward value management remains ambiguous. Although the use and application of digitalised processes has rapidly increased during COVID-19, it is not yet evidenced how this is going to make value management more tangibly integrated within the whole life cycle of a construction project. In motivating innovative processes within construction projects in the UK, the Construction Leadership Council [20] proposed a three-stage strategy (Restart, Reset, Reinvent) for the construction industry in an attempt to prompt innovative and functional mechanisms that support construction projects. Whilst such initiatives can provide robust starting points, recognising how value management is tangibly incorporated within it can be complex and difficult to justify. These complexities can be reasoned by the fact that value management does not rely on governed key performance indicators but often focuses on what the client desires, hence being perceived as a reactive requirement. Although 
some professional bodies such as the Royal Institution for Chartered Surveyors (RICS) have outlined a number of considerations (e.g., cost and waste reductions) when it comes to value management [21], a well-defined strategy that ensures rich considerations of value management across the WLC is yet to be paved, which can be reasoned by lack of governing value management integration in projects. Therefore, and during such uncertain times that face the construction industry during COVID-19, it is inevitable to consider different approaches and mechanisms that support more tangible recognition of value management as part of the WLC. This research aims to investigate the mechanisms that supports the delivery of value management and its integration across the whole life cycle (WLC) following the recovery from COVID-19 impacts. This is because many operations across the life cycle of a construction project are expected to change; hence, it is inevitable that key priorities such as value management maintain an integral part of the whole life cycle. It is important to indicate that the inquiry investigated in this research strives toward raising conjectural awareness of value management and what considerations it should encompass when the construction industry begins to recover from the impact of COVID-19.

\section{Contextual Background}

\subsection{Whole Life Cycle: An Overview}

Whole life cycle/costing can be defined to some extent in different ways, but essentially, it includes initial capital costs (land acquisition, design fees, construction), maintenance and refurbishment costs, operational costs, and disposal costs [10]. Fundamentally, a whole life cost study should identify where value can be increased or costs can be reduced for the entire lifespan of the asset [3]. Performing a whole life cycle on a project is not a sufficient source of adding value for clients and end users, therefore, WLC is used as a tool in the value management methodology [22]. Whole life cycle/costing requires a multi-discipline approach and should cover initial investment cost (site costs, professional fees, and capital costs), energy costs, operation and maintenance costs, replacement of components costs, occupancy costs, alteration costs, taxation costs, and salvage revenue and disposal costs [4]. WLC and value management are continuously interlinked as value management also requires a multi-disciplinary team which is structured, analytical, and systematic [3].

Kishk et al. [7] defines WLC as "the systematic consideration of all relevant costs and revenues associated with the acquisition and ownership of an asset". Flanagan and Jewell [10] similarly define it as "the total cost of a facility/asset over its operating life including initial acquisition costs and subsequent running costs". "Economic assessment considering all agreed projected significant and relevant cost flows over a period of analysis expressed in monetary value. The projected costs are those needed to achieve defined levels of performance, including reliability, safety and availability" [23]. NRM3 identifies whole life cycle/costing as "a methodology for the systematic economic evaluation used to establish the total cost of ownership, or the whole life cycle/costing of option appraisals. It is a structured approach addressing all costs in connection with a building or facility (including construction, maintenance, renewals, operation, occupancy, environmental and end of life). It can be used to produce expenditure profiles of a building or facility over its anticipated life span or defined period of analysis". Interchangeably with whole life cycle, the term 'whole life costing' is often more in use within the construction industry because of its application. For instance, when purchasing a car, one must consider several factors, such as the initial cost, insurance costs, service costs, maintenance and repair costs, fuel consumption, and the residual value of the car when it is sold. The concept remains the same within the construction industry, but with a more intricate approach [10]. It is important to acknowledge that whole life costing represents many (if not most) of the aspects/elements included within the whole life cycle, but terms are used interchangeably with minimal consciousness that can potentially cause a gap between industry and academia [24]. Although the economic side of the whole life cycle of a project is considerably significant, the social and environmental angles are equally important. This is because 
value creation/generation in a project relies on the synergy between different elements across all phases within a construction project; hence, life cycle goes beyond the economic considerations to even consider what environmentally (e.g., impact of environment) and socially (e.g., value for community) a project considers.

\subsection{Drivers of Whole Life Cycle/Costing}

\subsubsection{Literary Drivers}

A published report by Evans et al. [25] discovered that owning an asset had a ratio of 1:5:200 for construction costs, maintenance and building operating costs, and business operating costs, respectively, therefore the importance of conducting a whole life cycle study is paramount. Although this theory or hypothesis is not based on robust data and analysis, it does show the seriousness of whole life cycle/costing. Therefore, the document may not be scientifically accurate, but it did encourage clients to deeply consider whole life cycle/costing for future projects [26]. The universally recognised Latham Report [27] and Egan Report [28] are two of the most influential reports ever written for the construction industry. On the one hand, Latham Report recognised the need for an integrated working mechanism, which can support recognising value creation through interdisciplinary working mechanisms throughout different stages. On the other hand, and building on Latham Report, the Egan Report lensed the directions toward improving construction projects with particular emphasis on the need to integrate sustainability (environmental, social, and economic) more tangibly in projects and throughout the entire supply chain. Thus, it can be recognised that these reports outlined the need for stakeholders and in particular clients to consider various aspects that impact whole life cycle/costing. Although the industry has significantly advanced in terms of deploying latest technologies, adapting more lean processes to improve the whole life cycle, and striving toward procurement routes that integrate clients, evidence that illustrates value creation and management in construction projects is considerably limited and often associated with the nature (e.g., residential, commercial, etc.) of the project [27,29].

\subsubsection{Industry Drivers}

A major element for achieving a whole life cycle/costing assessment is multi-disciplines reviewing, analysing, and implementing of material changes, construction methods, operational performance, and decommissioning [30]. A WLC assessment will consider sustainability methods, such as material substitutes and fundamentally creating a 'net zero carbon' building [31]. An asset that has 'green' considerations and 'socially preferable' policies due to the WLC may carry a considerable higher purchasing price tag than its less sustainable counterparts [32]. Unnecessary costs can be derived from these aspects, which is why a value management process can be beneficial to construction projects. In essence, unnecessary costs can be defined as any additional cost that is imposed by any involved stakeholders in a project, which is carried out to improve function, quality, or optimisation of resources. Whole life cycle/costing helps identify and understand the costs [30], but value management is the solution to avoid unnecessary costs. Fundamentally, a whole life cost study aims to present all relevant and associated costs for an asset from the inception to disposal, therefore identifying comparable alternatives over a period of time and allowing the client to choose an option which best suits their needs and objectives [33].

\subsection{Barriers of Whole Life Cycle/Costing}

In modern times, the benefits of whole life cycle/costing (WLC) are broadly understood by industry professionals, but there are many barriers that are still detrimental to the successful application of WLC; therefore, the acceptance of the approach must be addressed. One of the significant barriers regarding implementation of WLC is the incentive for the clients and the lack of knowledge [34]. This can be reasoned by the fact that many clients often focus on the cost-saving side within the life cycle to deliver the asset while neglecting long-term value after delivery of the asset. For instance, with reference to long-term value, 
operation and maintenance of an asset can be recognised as a significant aspect, which has an impact on management of the asset and has direct influence on occupants' experiences, and this can indeed reflect poor value management within a project. Elaborating on this, Othman et al. [5] discovered that one of the reasons value management strategies are not being implemented is because of the absence of awareness and knowledge of value management. This can perhaps be associated with limited and narrow understanding of WLC, many clients tend to focus on cost-saving elements within a project [33]. Generally, clients will be demotivated to implement value management within the WLC because their main priority for an asset is efficient and effective execution with cost-cutting solutions [7]. Bull [35] and El-Haram et al. [34] highlighted that one of the reasons behind lack of understanding of the wider picture of WLC is the deficiency of reliable, relevant, and appropriate historical information and data, including for the performance of buildings, which are fundamental for the success of WLC. Moreover, WLC is surrounded by unreliable cost- and time-related data, which causes the industry to lose trust in its method [31]. Although some organisations have samples of reliable information and data, one reoccurring barrier among authors is there are no universal methods or standard formats for calculating WLC [23]. In addition, Wong [30] also highlights a major barrier being the processes, such as when to perform a WLC assessment or who should be involved. Similarly, Cheah and Ting [35] concluded value management was not being implemented because of the lack of expertise and technical standards, thus being comparable to the application of WLC. WLC requires many considerations, but construction projects are still focusing on initial costs rather than other aspects that can also add considerable value [36].

\subsection{Value Management: An Overview}

Broadly, value management is a process that can add value to the client in terms of the end user and profitability, which can also ensure cost certainty [37]. Value management is also perceived as a structured technique that facilitates multi-disciplinary team members effectively deciding on the 'best value' for a project [4]. The 'multi-disciplines' consist of the client, main contractor, sub-contractors, specialist sub-contractors, suppliers, manufacturers, architects, quantity surveyors, project managers, and other involved stakeholders [7]. Value management should be exercised through a series of workshops, interviews, and reviews, which should clearly identify the clients' and project stakeholders' objectives and the methods of achieving them [38]. It is essential that value management is an integral element of a construction project, especially with projects viewed on a whole life basis, such as private finance initiative [38]. During these workshops or meetings, multi-disciplines will identify specific issues then use one of the fundamental techniques, which is function analysis [23]. This allows a 'systematic breakdown of functional requirement' and concentrates on the aspirations from the project stakeholders and clients. Value management essentially identifies unnecessary costs within the construction project and considers alternative solutions without detriment to the functional performance, aesthetics, and safety, while also benefitting the projects schedule and whole life cycle [22].

Simultaneously to the above, it is equally imperative to integrate and consider the social and environmental aspects as part of value management, as this would ensure holistic consideration of sustainability, and more importantly, maintaining the value stream of the project on the long term. Therefore, it is critical to the process that value management an early running thread that is considered throughout different stages with the input of a multi-disciplinary project team [4]. Over the years, major efforts by research and practice attempted to set the ground for value management so it becomes more integrated within construction projects. One of the models (see Figure 1) produced provided a five-step model for value management which commences by analysing issues, moves to analyse functionalities, proceeds to innovation, then identifying cost reductions and adding value, and concludes by action planning. Although such conceptualisation of value management can demystify where to commence when attempting to integrate value management, 
situating where it fits in the supply chain can be complex, and more importantly, indicating how this is governed throughout the whole life cycle is very vague.

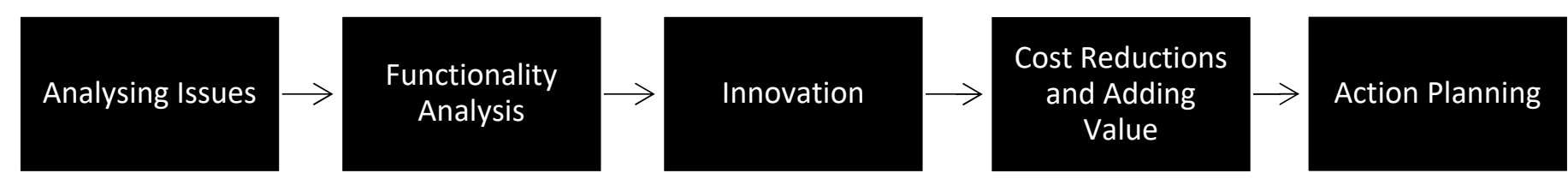

Figure 1. Generic model of the value management process [39].

\subsection{Value Management: Impact on Construction Projects}

Commonly, both terms (value engineering and value management) have been used interchangeably as they both contain each other and a value management strategy cannot be executed without value engineering and vice versa. Fundamentally, value engineering is used as a technique to reduce the initial capital costs, mainly the construction costs. Value engineering is first implemented when the project can be defined by its elements and components, then it is completed at the end of the construction phase [35]. Value management is introduced at the inception stage of the project and its technique is executed throughout the entire lifespan and ends after the disposal stage [9]. In essence, value management is a 'systematic breakdown of functional requirement', whilst value engineering is delivering specific functions at lower costs, but without detriment to the quality, performance, and reliability [20].

One of the major drivers of value management within construction projects is the integration of lean processes [40]. Lean can be recognised as one of the big pictures when it comes to value management, which can be reasoned by cost reductions, sustainability, improved considerations of health and safety, and increased productivity [41]. Many research efforts (e.g., [42,43]) have highlighted the role that lean approaches play in terms of delivering value management within construction projects. Lean construction, although it brings major benefits to construction projects, can be challenging due to resistance to change, lack of knowledge by stakeholders, or even the nature of the project itself.

Choosing the right facilitator for the value management of a construction project is absolutely essential, as they must have the necessary skillset to lead, manage, direct, guide, and control other team members to help them harmonise with the key principles, standards, and techniques of value management [21]. Generally, a discipline with the correct knowledge and understanding should undertake the role of facilitator; therefore, a quantity surveyor is generally a perfect fit, as they are the central profession concerned with the project costs [44]. Cost planning is one of the core competencies for quantity surveyors, and within that competency is value management [45], which clearly identifies the importance of value management, but also the importance of the facilitator.

\subsection{Value Management: How Crucial Are Stakeholders' Perspectives?}

It is paramount in the early stages of a construction project that the needs, objectives and aspirations are clearly identified by the client and the involved stakeholders [4]. The application of value management always depends on the level of risk and value the project bears, thus high risk and high value requires absolute attention, therefore low risk and low value is not generally necessary [46]. As shown in Figure 2, 'strategic security' (high risk, low value) and 'tactical profit' (low risk, high value) would only generally require a desktop value management study, which does not require stakeholders to set up workshops, interviews, and reviews, but requires value management to be completed in a less collaborative manner [38]. This illustrates that one of the constituents for value management is stakeholder integration and leveraging this strategically so that it positively reflects on the whole life cycle. Figure 2 in fact raises an important point, which is that value management in projects, beyond being an integral part in a project, is project-dependent, and does not have one-way or fixed approach to achieve it. More importantly, although 
the research conducted [34] nearly 20 years ago shows that it is important to have a value manager, it does not discard the necessity of integrating different stakeholders in defining value management within a project.

\begin{tabular}{|c|l|l|}
\cline { 2 - 3 } \multicolumn{1}{c|}{} & High value & Low value \\
\hline $\begin{array}{c}\text { High } \\
\text { risk }\end{array}$ & Strategic critical & Strategic security \\
\hline $\begin{array}{c}\text { Low } \\
\text { risk }\end{array}$ & Tactical profit & Tactical acquisition \\
\hline
\end{tabular}

Figure 2. When should value management be applied? [38].

The decision for a client to take on a new project requires considerable investment, in terms of time, effort, and money, and it should be of utmost importance to squeeze as much value out of the project as possible [9]. It is essential for the success of the project to identify the key project objectives and prioritise these effectively [39]. Value management allows the project team to identify issues and produce a functional analysis before making huge financial commitments, thus allowing the client and stakeholders to foresee any financial difficulties [45]. The approach analyses the project design and ensures that the most effective methods and strategies are being enforced in terms of cost, quality, and satisfying the long-term needs of the client [24]. Due to its multi-discipline methodology, it sets a precedence for synergy, innovation, and developing new skills, and motivates the project team [45].

During the inception stage of a project, value engineering or management should be a priority and considerations must be made, including the availability of materials and labour, construction methods and skills, transportation, site restrictions, and costs [47]. These considerations contribute to the reduction in life cycle costs, which is why value management is such a powerful tool for whole life cycle/costing [22]. Modular construction is a modern method of construction (MMC) that has become increasingly popular in recent years, although it can be dated back to 1837 [48]. Modular construction is a way of building components off-site and under factory conditions, then transporting to site where they can be assembled using a crane [49]. If the client's objectives allow for this type of construction, the benefits can be enormous in terms of sustainability and reducing cost and time. Modular construction minimises material waste by up to $90 \%$ due to controlled building environments and eases the site constraints and traffic, as $80 \%$ of the construction activity is taking place off-site [50]. In addition, this technique allows the modules to be built concurrently with the foundations and other site activities, therefore reducing the schedule by up to 50\% [49]. One of the main benefits of this method is the added quality of the component due to the factory conditions and acquires a higher sustainability standard in accordance with BREEAM, PassivHaus, and ACEB [51]. Moreover, the energy consumption in modular buildings is generally lower than traditionally built schemes [52]. In terms of cost, materials, and wastage, it can see a potential saving of up to $15 \%$, labour is reduced by up to $30 \%$, and preliminaries are reduced, resulting in approximately $7-10 \%$ savings in contrast to traditional building [53]. For example, it is common to have an increased demand for bricklayers or bricks; therefore, in times like these, this method can be implemented with maximum effect. To conclude, modular construction will result in a reduction of cost and time whilst adding quality and sustainability standards, which supports the core purposes of value management. 


\subsection{Challenges of Value Management}

Value management has certainly had its negative impact on the industry as clients and project teams try to implement cost savings methods. Most recently, there was the example of the fire that caused devastation at Grenfell Tower, London. The exterior cladding on the building was originally using zinc, but it was later changed to aluminium to save on costs, consequently allowing the fire to rise through every level of the building [54]. This was a clear misuse of value engineering and proves that some clients will try to cut costs without considering the quality, performance, or reliability of a specific material.

After an extensive study into the industry's use of value management in Cairo and Giza, Othman et al. [5] identified 23 barrier variables. The four substantial barriers were insufficient facilitation and preparation, weak coordination, and working relationships between the stakeholders [5]. In developing countries, such as Nigeria, it was found that their knowledge of value management is moderate among professionals and their intent of adopting the method is the core issue; consequently, the need for training and education is paramount [55]. Value management requires great collaboration between stakeholders and applying this method can often be perceived as critical to their designs, which can result in project stakeholders becoming frustrated and showing a negative attitude towards the process [56-58].Value management is a method that is widely used in the construction industry today, so academic institutions and professional bodies should be implementing awareness and training for the adoption of VM at the early stages of design, as there is a significant knowledge and skill gap [59].

\subsection{Value Management: Impact of COVID-19}

Over the years, there has been extensive publishing work that has helped improve the value management and whole life cycle/costing of construction projects. In 2018, the construction industry contributed $£ 117$ billion to the UK economy, which was $6 \%$ of the total economic output [60]. It also employs around 2.4 million people in the UK, which equates to around $7 \%$ of all jobs in the UK [60]. According to a survey produced by Construction Online, $87 \%$ of construction businesses have been affected by the pandemic and $62 \%$ of businesses have suspended operations in some form because of COVID-19 [61]. Although consecutive economic growth in the construction industry took place during the COVID-19 period, the level of output remains 10.8\% lower than it did pre COVID in February 2020 [62]. The government and the Construction Leadership Council (CLC) have produced the Roadmap to Recovery; An Industry Recovery Plan for the UK Construction Sector [20]. The plan outlines a restart, reset, and reinvent strategy for the UK construction industry.

During these uncertain periods due to COVID-19, clients, contractors, and all project team members must still be making value management and whole life cycle/costing a priority, thus the government and the Construction Leadership Council have produced a plan to get the UK back on track. With the introduction of the plan "Roadmap to Recovery" by CLC, there are some suggested mechanisms to help the industry provide additional value for construction projects. However, considering the reviewed literature, it can be stated that value management within construction projects, beyond its narrowed focus on the financial side, lacks the incorporation of long-term values such as sustainability and relies on clients' preferences. More importantly, it is not evident that value management is not governed, which shows that its presence in a project is optional and may not be tangibly considered as part of the whole life cycle. Although the impact of COVID-19 has motivated the use of more digitalised solutions and implementing them throughout the whole life cycle, it is not clear how value management can be positioned within a project, and it is hard to predict whether there will be drivers to motivate the integration of value management within the whole life cycle/costing. The need for clients to turn their focus from initial capital costs to whole life value during a global pandemic could be under threat, therefore it is essential to acquire insights and experiences from those who often 
drive value management within projects, hence focusing on obtaining primary evidence from quantity surveyors.

\section{Research Methodology}

This study will use a qualitative approach through a focus group, as this approach allows for answers based on experiences, perspectives, and their own opinion [63]. Moreover, the focus group approach displays respondents' attitudes, feelings, beliefs, and experiences in a way that quantitative methods would often fall short in providing. The selection of participants followed a critical purposeful sampling process [64], which primarily targeted quantity surveyors as they are often concerned with justifying value management integration within a project [65]. The sampling strategy followed purposive sampling [66] which required particular criteria in order to draw meaningful and more focused evidence related to the research inquiry. The criteria included years of relevant experience (minimum 10 years) across different types of projects (public and private), type of projects (e.g., residential, commercial), experience of working closely with clients, familiarity with different procurement routes, and knowledge of advanced technologies (e.g., BIM) in construction. A total of six UK-based quantity surveyors from four different-sized (large contractors, small medium enterprises, and consultancies) organisations. The number of participants included in this study corresponds to the recommended number (6-8) suggested by many scholars in a focus group [67]. The small number can also be reasoned by the criteria set to select participants and the limited accessibility caused by COVID-19 where the means of contact was mainly online.

This research study uses thematic analysis, as it offers a structured yet rich approach to identify complex areas that support tackling the research problem investigated [68]. All participants involved in the focus group were assured that any information or data given would be managed with the strictest confidentiality and no personal data would be disclosed. Participants were notified that they could exclude themselves at any point and any information given would be destroyed and appropriately dealt with at the end of the research study [65]. The focus group included seven questions, which focused on defining the perspectives of quantity surveyors, how they integrate them in a project and governance and whether there is a well-defined process for it, education and training, and the impact of COVID-19 as well as the role of technology. The focus of these questions was rationalised by gaps identified in the literature and the need for different experiences to support understanding what strategies need to be incorporated to integrate value management more tangibly in projects. The following are the questions that were included in the focus group:

Q1: In your opinion, do you see value management as a client-associated aspect or an essentially integral part in the whole life cycle?

Q2: Based on your experience, do you believe that value management should be governed by professional bodies such as RICS? Why?

Q3: In terms of value management, is there a structured or well-defined process that is usually followed? What is your role as a Quantity Surveyor in defining the value management process?

Q4: Within your organisations, is education and guidance offered to support the development of different professions of value management and what role it plays in a construction project?

Q5: During COVID-19, do you think that value management needs to be looked at differently? If so, why, and if not, why not?

Q6: Do you think that guidance by the government (e.g., Construction Leadership Council 3-step strategy) for post COVID-19 recovery will support more tangible integration of value management in construction projects?

Q7: In your opinion, what role would technology play in supporting the integration of value management? 
It is important to indicate that, although value management is primarily concerned with clients, they were not involved in this study. The main reason is that, in construction, there are many client types (e.g., public or private) and clients' knowledge of value management is often related to profitability and cost cutting rather than holistically considering it at a whole life cycle level. Therefore, the focus group supported stimulating different experiences of working clients from the quantity surveyors' perspectives. It is anticipated that the subjectivity of data will support deriving dimensions and mechanisms that support formulating a strategy for value management in projects.

\section{Results}

The data obtained through this focus group will help establish the fundamental processes surrounding value management (VM) at four UK firms across London and Birmingham. The session lasted for circa one hour during which all participants discussed their opinions and future beliefs for VM pre and post COVID-19. The focus group consisted of seven questions (see Section 3), which stimulated an in-depth discussion to find out how different companies from different locations implement and vision VM within construction projects. The focus group will help understand whether UK firms are trying to implement new strategies to help advance VM post COVID-19 or whether they are wasting their time reinvigorating something that already exists. Line-by-line coding was used in order to code the responses gathered from participants where the answers were categorised into four themes. These four themes (see Figure 3) are 'between perspectives and governance', 'is there a defined process', 'between pre and post COVID-19', and 'technology'. To keep the confidentiality of the participants, as promised by the author, they shall be referred to as A, B, C, D, E, and F. To ensure the reliability and validity of the data gathered, the focus session was transcribed and communicated back to the participants who agreed and consented to the transcribed data.

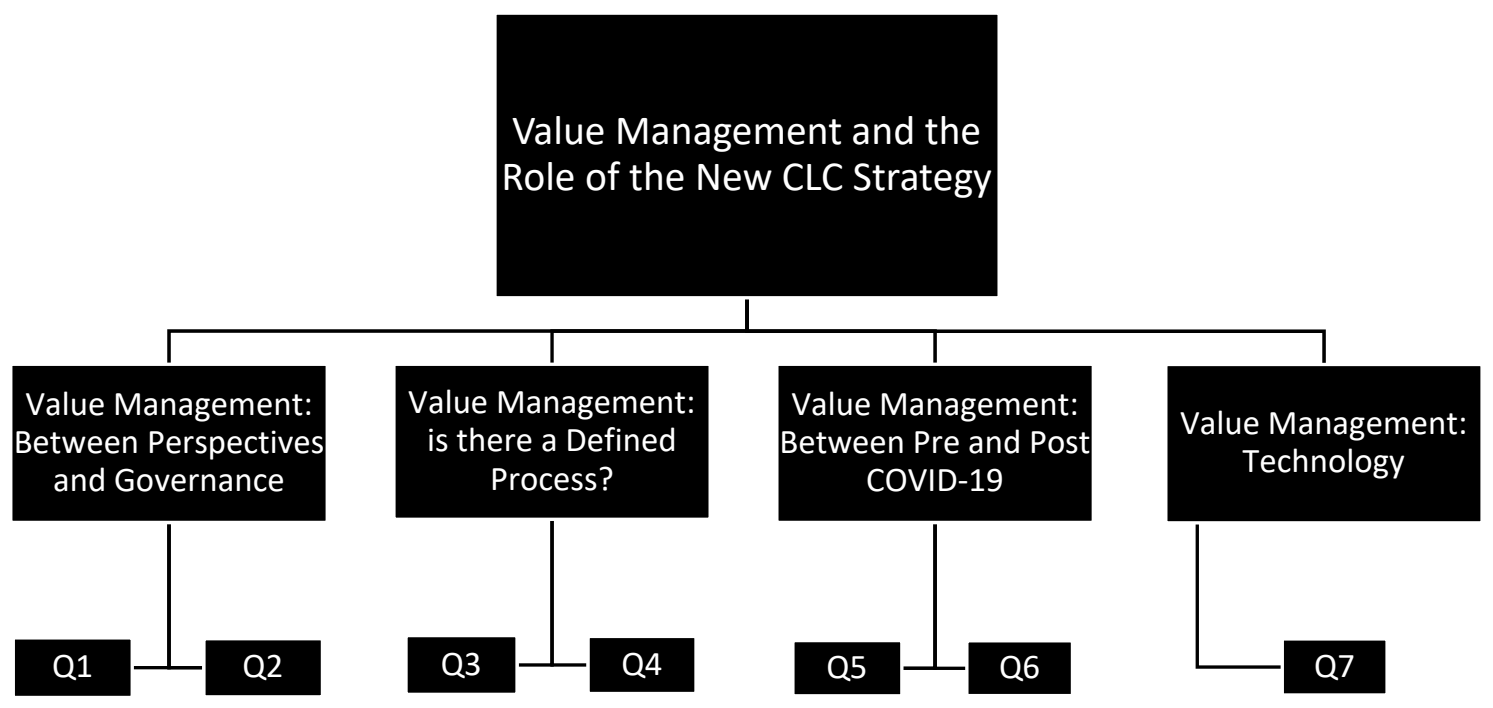

Figure 3. Themes derived from the focus group.

\subsection{Value Management: Between Perspectives and Governance}

This theme aims to reflect the knowledge of six quantity surveyors and understand their perceptions of value management to see how they believe it should be implemented within their firms, as well as whether they believe that professional bodies such as the Royal Institute of Chartered Surveyors (RICS) are doing enough to push the process and strategies for construction projects. In addition, the intention of this theme is to help understand if UK firms are trying to implement more inventive strategies to help drive VM post COVID-19, or whether the same traditional processes are still being applied.

The first answer to question one by respondent E: "it depends how you define value". 
Additionally, respondents A and F added that "it depends on what situation you are in, so we'll get to a stage where we are over budget or we need to save a bit of money and we'll rapidly go through and find a few ways of making that happen." Respondent $\mathrm{E}$ replied: "if you're looking at a whole life cost, then we might lean on whether this is the right decision for the client and whether they are looking to keep the asset or sell the asset at the end of the project."

Respondent C, who works for a large London consultancy, also added: "yes, I would agree with that, in practice VM as a method is not used in any way other than to reduce cost. We would look at it and see whether there is any point in putting this extra money into the project when the client will be selling the asset either straight away or after a couple of years."

Respondent A then added: "you can use it in conjunction with an appraisal to sort of reset the budget for a different amount of work. If they're only interested in a certain yield on the client side, then you can tweak bits to make that happen ..."

From the responses above, it was perceived that value management is generally seen as a cost-cutting solution and is not perceived as adding value for the client. The evidence from the participants suggests that VM is not used as a strategy to add value at the start of the project, but it is a method of cutting costs for the client to make an asset more profitable; however, it seems likely that it is client dependant. These responses strongly suggest that although value management can be added for the client during an appraisal, the ultimate aim remains spending more money for a higher return, therefore constantly only considering the profitability of the project for the client.

Respondent E said: "value engineering is a reactive process and value management is a strategic process" to which respondent B replied "to say it's a strategic process I'm not sure. I don't think I have ever worked on a project where it's been used as a strategy on a project." Then, respondent $\mathbf{C}$ added "yes, I would completely agree with that, I have never done a VM exercise at the start of a project, but I have definitely done a VE exercise when we are over budget."

There is evidence from respondent $E$ that suggests value management can be used as a strategic process although respondent $C$ and $B$ strongly disagreed. Some may argue that it is used as a strategy, but respondent $C$ and $B$ have many more years of experience compared to $\mathrm{E}$ and neither has used it as a project strategy. It was stated by the majority of the participants that the whole concept of value engineering and value management has only ever been used as a cost-cutting solution when the project becomes over budget.

When asked if professional bodies such as the RICS should govern value management respondent A answered: "There is a guidance out for best practice. It is not governed but it is a guidance and if the worst happened then you could be liable." Respondent $E$ then added: "Yes, it is basically just a guidance, which can be used if you want for best practice, but it is not a legal obligation."

Both of these respondents believe the guidance by RICS is sufficient for the industry. However, as they believe value management is only a cost-cutting solution, maybe RICS should be doing a lot more to educate the industry on the benefits of the process.

For this theme, it can be stated that value management is mainly used as a cost-cutting solution and not for adding value for the client as an early strategy. Arguably, although participants stated that value management could be perceived as a strategic process, they believed that it was client dependent, and hence seen as a reactive process in a project. It was also added that participants seemed to agree that the guidance provided by RICS is efficient enough and should not be governed or be a legal obligation, as they believe the idea of value management as a project strategy just does not exist, but is often considered to reduce costs.

\subsection{Value Management: Is There a Defined Process?}

The purpose of this theme was to inquire into the structure and processes that underline value management within the industry. Moreover, who should be involved in 
the driving value management and indicate the influential disciplines to the process? In addition, this theme also looked into organisational-related training and guidance behind value management or whether the participants believe that formal training should or should not be given.

The first respondent D said: "I think it's completely specific and dependent on what stage you are at, whether you have been given a budget yet or you've produced a stage 4 cost plan, which is going to tell you how you go about that exercise." Respondent $\mathbf{C}$ replied "it's the preference of the client, in my experience we have done it through workshops when we are doing it as a reactive process, so we get the designers round a table and discuss ideas on how we can value engineer the project ..."

Respondent A added: "and at the same time it can get tagged on a DTM [design team meeting] because all the people needed to be in the room are there." Respondents B and F replied "yes, so for example, generally, we discuss VM or VE without even realising at DTMs (Design Team Meetings) so it can be structure for design, but it isn't categorically said this is a meeting for VE or VM ..."

From the above responses, there is an indication that value management is not necessarily considered at the early stages of the project and is primarily dependent on budget issues within the cost plan. In terms of the process itself or when value management takes place, respondents claimed that it often takes place during the design team meetings where discussions on how to embed value management takes place, but they also highlighted that there is no formal process that value management is built on or followed in order to illustrate it in a project.

Elaborating further on how value management is defined within a project, respondent E stated: "For VE/VM you just get sent a big list of considerable items and told to price this and choose which option were going to use ... you price it and the PM (Project Management) chooses whether that's a good option for the project ... you're not involved in the VM process until near completion when you start to realise you're over budget ..."

In fact, commenting on the above response, participant A pointed out the following: "I feel like if facility managers are involved at much earlier stages, they can absolutely change how we incorporate VM properly, so when you're talking to FMs all the time you tend to consider the life cycle more, as they know how the building works when it's all up and running ... " Subsequently, respondent D added: "that also ties in the post contract changes if the FM comes on after you've signed the contract and then the change ends up costing you a lot more money than it would if you put it into the design and the design phase."

The above responses suggest that, beyond quantity surveyors, there are key stakeholders that also play a part in defining and driving value management. For instance, the project manager is clearly a major part of the value management process, as they have to decide whether specific items are right for each project, as described in this instance, the respondents circle back to when they are realistically involved in the value management process, which seems to be when they find out they are over budget and need to react to the situation. Aside from project managers, although many respondents knew what facility managers are, the majority of respondents were not aware of their importance to the value management process. This is because one of the participants was assertive that a facility manager has the knowledge that is fundamental to the value management process and they can save clients unwanted costs but persuading the client to pay for a facility manager for a value management perspective can be difficult. Another participant suggested that a facility manager can play a significant role in terms of cost efficiency if they are involved during the design stage rather than being limited to only being involved during post contract stage.

When asked about guidance and education for value management, participant $\mathbf{A}$ replied: "no formal training is in place with it and it's a more do and learn kind of exercise ... Some jobs you need to change the flooring, or wholesale changes or full redesign", to which respondent $C$ replied "no we don't give any formal training either. When you first 
start you don't just do a VM exercise on your own, but you are present in the process with your peers, so I suppose that is a part of the training but definitely no formal training."

Respondent F also added: "the only time something like this came up for me was when I was working at a UK firm and they had their own value and risk team. They come round the offices to show what they do but that was to basically upsell their service as opposed to teaching everybody." Respondent E added "I think it is a learning curve working with different clients, they are different, and what concerns a client may not concern another, but generally they are after cost-cutting solutions"

Both of these respondents work for well-established cost consultancies in London and have not received any formal training, which is also a reason why the majority of participants did not comment or provide feedback on this question. The responses received show that the value management process is indeed learned through experience and when the opportunity arises, as formal training would be another unnecessary expense, and more importantly, that working clients are the main hub to understand and learn about value management across different projects.

From this theme, it can be stated that value management as a process does not exist, but it is actually discussed during design team meetings. However, this is completely dependent on the stage of the project and is not specifically labelled as a value management 'meeting' or 'workshop'. The participants suggested involving a facility manager at the earliest possible stage, which will likely result in better long-term value for the end user and better profitability for the client. This theme showed the importance of a project manager as well as a quantity surveyor, as the participants suggested they have the final say on specific items. In addition, the participants advised that a facility manager can have a huge effect on the value management process, but they are often appointed post contract when changes occur, which a facility manager could have prevented due to their knowledge and understanding of building mechanics. The participants believe that formal training for value management does not occur and it is only learned through on-the-job activities with their peers. It was also indicated that working with clients, although their perspective seems to be cost-focused, is the main learning curve that they rely on to understand and develop their knowledge of value management.

\subsection{Value Management: Between Pre and Post COVID-19}

This theme aimed to highlight responses with relation to the value management process between pre and post COVID-19. The aim was to distinguish whether the participants believed that change is happening or whether a change needed to happen to aid the industry. Moreover, this theme aims to establish whether the industry bodies should be interacting with construction firms about the Construction Leadership Councils' (CLC) plan to re-invent the industry or should the CLC be imposing their plan themselves.

Respondent A answered first with the following: “ . . clients were putting in everything COVID safe related into their fit out, like automatic doors, sensor taps and stuff like that. Hand sanitiser stations everywhere just so they could charge and bit more rent and say we are COVID safe" to which respondent $C$ replied: "Some time over the summer we had a client asking for COVID features in their offices, such as low contaminated surfaces, sensor taps, kick plates or automatic doors, just so they could put a stamp on their sales brochure to say they're COVID secure, which makes it more saleable".

Respondent B added: "Amazon did a CAT B fit out and had me put in rolling furniture, so if they had to social distance, they could create the layout of the furniture easily and quickly. So, in 6 months, if they don't require a COVID layout, they can change it extremely quickly ..."

These responses show that the industry, although it is responding to COVID-19, the main focus is on profitability for projects, which seems to be the main aim for their clients. This reflects that value management is still seen as a reactive process and shows desire to continue using techniques that support cost-cutting solutions for future projects. Moreover, they believe their clients were only putting in COVID features as a planned sales method 
to either make it more profitable or easier to sell instead of actually installing these features for the end user. One of the respondents, although it may be perceived as irrelevant to construction industry, stated how organisations from other industries such as Amazon demonstrate embedding value management for a client/consumer by focusing purely on the value it brings their business instead of the profitability of the asset. In this instance, the client has recognised that during the global pandemic, the use of moveable furniture can turn their office into a smaller and larger capacity within minutes, thus enabling them to continue working. However, the respondents suggest this is entirely dependent on the client and the majority of clients do not want this level of detail spent on their asset.

After questioning the group on the Construction Leadership Councils' re-invent plan, respondents C and F answered: "just looking at this CLC and you should have a look at alliance in models which is quite a big thing now and even NEC have brought out a contract for alliancing. The CLC is the same where it's not really for a developer coming in and building a residential project..."

Respondent D also added: "you have office developers now that go all out to achieve accreditations like BREEAM and WELL but they just do it for brochure so they can put the prices of their rent up ..."

Bearing in mind that most respondents were not aware of recovery plans for post COVID-19 such as CLC, some respondents believed that developers just trying to make a profit will not be looking at the CLC's plan to re-invent the industry, but clients who want to build an alliance through multiple projects will be more inclined to collaborate and help provide value to the end user. Furthermore, he explains how collaborative working only works for specific projects and traditional methods can be better suited, therefore the CLC should consider that their ideas are not always the correct ones depending on the specific project. Additionally, another respondent pointed out that there are clients out there trying to do these accreditation schemes, but only to make their asset more profitable.

From the above theme, it can be stated that the participants believed it was clientdependent how much detail they wanted to spend but making the asset COVID-friendly was a calculated sales approach. The participants detailed how COVID features are being introduced to the industry within their fit-out designs but adding value through digital and manufacturing technologies seems to be a far reach to re-invent the industry. However, the participants suggested that accreditation schemes are being implemented but it is another sales method to make an asset more profitable, which is becoming a common theme. There are subtle changes happening within the industry pre and post COVID-19, but according to the participants, these changes will not greatly affect the industry. The discussion generated in this theme can reflect, beyond complexities associated with understanding value management in projects, that there is a need to define aspects that act as inputs to value management, and how this differs across various projects. More importantly, there is a need to bridge the isolation between industry and government plans to maximise the recognition of value management in projects.

\subsection{Value Management and Technology}

This theme aims to focus on how technology is impacting and influencing value management within the construction industry based on the participants' responses. This is related to the research problem in finding out how technology can support more recognition of value management post COVID-19.

When asked if technology would play a pivotal role in supporting and driving value management, respondents E and B replied: "technology-wise, I'll go back to my point on facility managers. If they're involved at the early stages, it really assists in the selection of materials and that part of the design ... BIM is more collaborative 3D design where they can clash detect their design, but key to this is having an FM (Facility Manager) early on."

Respondent A also added about BIM: “ ... but somebody has to pay for this privilege, and nobody actually does or wants to. They take the little bit of value that comes with 3D modelling, clash detection, and bits and pieces like that, but don't really need the rest of it." 
Respondent A added: "but where its mandated for government projects, it probably has more of a future in it, just because everybody will be up and running if they're working on government projects and they'll have all the kit, know how to use it and roll it out to other projects ..."

Respondent A shrewdly indicated that the capacity for BIM is not feasible for one off clients or developers, and therefore they are not interested in using it. Furthermore, respondent A suggested that only people who regularly work within government projects have sufficient education on BIM, which is a small percentage of the industry. More importantly, it was expressed how the cost of deploying advanced technologies such as BIM does not outweigh the benefits for the client, therefore clients opt to avoid using it. Another respondent indicated that although BIM has its advantages, such as clash detection, maximising value of such technologies would require more tangible integration of key stakeholders such as facility managers with the experience and knowledge to help find better value for the client in the earliest stages; for instance, expressing how many people can occupy a space before it affects the oxygen levels in a room, therefore showing how a facility manager can be more beneficial than new technology.

On the use of advanced technologies to support more recognition of value management, participants F and D stated that "as quantity surveyors you know, technologies like BIM may not directly benefit us, but it can certainly be good to recognise value management through sustainable solutions like modular construction, or even involving the wider community you know ... ". Participant C commented on this: "yes, I agree, I think there is a good deal from these technologies that we are not fully recognising but it can definitely support better value for projects"

The participants that answered in this theme showed that technology is not at the forefront and they do not believe it to be the answer for the industry post COVID-19. However, if government projects are made more attractive to the average client, then using technology such as BIM during their projects could widen the education on the process. Furthermore, they believe that key stakeholders such as facility managers can play a pivotal role in adding value to the client at the earliest stages of projects, which is thought of as a more practical approach in improving the value management process. It was concluded that the industry should be alerted to the opportunity of integrating lean solutions such as modular construction and engaging wider community to maximise value in projects.

\subsection{Summary of Analysis}

It can be said that the participants perceive value management and value engineering as a cost-cutting solution for their clients. They believe value management should not be a contractual obligation and the RICS guidance is efficient enough for the industry to adhere to. The participants suggested the process of value management is implemented indirectly through design team meetings, which is seen as a perfect opportunity to discuss the budget issues. In addition to a quantity surveyor, the project manager and most importantly a facility manager are the most influential disciplines to the process. Moreover, the participants pointed out that digital technologies such as BIM would not be the answer to re-inventing the industry, but appointing facility managers from an early stage has the potential to be. Furthermore, the industry has started implementing COVID prevention features into their fit-outs but generally this is used as a strategic sales approach. In essence, it can be stated that the industry's reaction to the pandemic needs to holistically capture strategic mechanisms that support more tangible integration of value management.

\section{Discussion}

\subsection{Value Management: Reactive or Proactive}

Reviewing extant literature and according to Kelly et al. [1], value management has moved from using the process as a cost-cutting tool to adding value for the client. Nevertheless, based on the responses from theme one and two, it was evident that value management was a cost-cutting tool for the client and therefore a reactive process. The 
RICS guidance on value management is a competent framework for the process, yet it is not a legal or contractual obligation, thus the entire value management process becomes reactive instead of proactive. If a legal dispute is raised within construction projects, then a court or tribunal can request a reason as to why good industry practice has not been implemented [44]. However, it was evident during the focus group that value management processes are not being considered and implemented properly, therefore a legal or contractual obligation through procurement may be in the best interest to make the process proactive. A couple of the respondents in the focus group spoke about how their clients are not interested in value management, as they work in high-end residential and commercial sectors, however, they still react using value engineering to reduce costs. If their clients believe that high-end sectors do not require value management strategies, then they need to switch their mentality to reap the benefits.

Value management definitions often target value creation for the whole life cycle $[4,39]$, but this would require a more holistic (top-down) thinking to support driving different aspects that support this and potentially move away from a bottom-up approach, which is often the case. The focus group showed that the final outcome for clients is essentially to make as much money as possible from an asset, and adding value can be a strategic sale approach; however, a proactive value management strategy with the help of a competent facility manager could save the industry a small fortune. Projects viewed on a whole life basis will benefit more from an early value management strategy, but as the method is client-dependent [69], it is likely most clients will not adopt this strategy if they want a quick return on investment. Literature has uncovered that clients willing to involve themselves in the value management process see the benefits and try to implement it within their projects; however, clients that do not involve themselves in the process regard it as unnecessary [70], but if the process was ingrained within every project, then they would see the benefits it has. The biggest issue arising from these themes is the participants not understanding that value management is imbedded in the process of construction projects, therefore they only react when prompted by budget issues and in turn by the client. When a project is in a familiar situation where they are over budget, value management is used effectively to reduce initial capital cost [39]. However, if these strategies were in place pre contract, then costs could be significantly reduced and accreditation schemes could be applied without additional expense. It can therefore be stated that value management, in order to move toward a more proactive approach, needs more holistic strategies through defining robust grounds that act as pillars to drive value management for the whole life cycle.

\subsection{Value Management: What Has COVID-19 Prompted?}

COVID-19 has had a devastating effect on the construction industry, but it has allowed for more strategic and inventive approaches [71]. The pandemic has evidently not forced UK firms to consider value management in more depth, but it has made people more aware of the benefits it can have, such as new COVID features in fit-out designs. Previously to COVID-19, the common trends for office designs were to promote collaborative working spaces, open plan, hot-desking, and basically areas that are contrary to social distancing [72], but now the materials for desks are being considered so that bacteria perish on worktops. During the focus group, it was discovered that the industry has started to encourage COVID features in their fit-out designs and has been able to put a COVID stamp on construction projects, which has also been widely used as a strategic sales approach. During COVID-19, there were two approaches that UK firms could have taken in terms of value management: using it as a cost-cutting solution or digital transformation. Extant literature has been of the agreement that value management in the construction industry is moving away from being a cost-cutting tool and started using digital technologies to push the industry into the future [1], yet from the evidence attained during the focus group, it was clear that value management was and is being used as a solution to reduce costs. However, there are many aspects that can be digitally controlled. 
Professional bodies such as the RICS's guidance on value management is something most experienced quantity surveyors are fully aware of, but inventive strategies, such as including a facility manager at the earliest possible stage, is a strategy that may be unknown to the majority of quantity surveyors. Value management has been subject to several research papers and books, such as Connaughton and Green [73], Oyedo7apo et al. [13], and Jay and Bowen [61], to name a few, that outlined how to effectively implement VM strategies into projects, but these ideas seem to be obsolete or not being used. Therefore, new research to develop the industry post COVID-19 is essential for the industry to progress. The guidance, procedures, and information on value management by governing bodies is insufficient, so it is not being used effectively or providing industry professionals with the knowledge they need to implement a successful value management strategy [5]. COVID-19 has shown the industry it needs to evolve to be more streamlined and efficient like other industries; therefore communication between the government, governing bodies, and industry professionals needs quick improvement. However, this was already outlined in Latham's [27] report, thus the industry needs to take action to apply these changes, as recent evidence shows that it is not working. RICS should be offering a forum which is governed by themselves and investigates new creative strategies that quantity surveyors are applying around the country but are relatively unknown to the rest of the industry. In Rahman's [74] report about collaboration, he writes about the importance of sharing knowledge and information and how it is one of the most important aspects for the industry to succeed. Most large UK construction firms have an innovation team and the members imbedded in these teams need to be in communication with RICS to showcase their skills. Therefore, they can be shared to help improve the future of the industry. In terms of education of value management, formal training may seem unnecessary, but governing bodies such as RICS could help educate the industry through presentations at offices to show the significant benefits that real-life value management strategies have had on projects.

\subsection{COVID-19: An Opportunity to Strategise Value Management for the Future}

There are so many great authors that have contributed towards the implementation of value management, such as Sir Michael Latham [27], Sir John Egan [28], Flanagan and Jewell [10], and John Kelly [1], to name a few; yet a holistic mechanism such as value management still has an overbearing problem. Most quantity surveyors and especially the participants in the focus group are well aware of value management and understand the concepts [65], yet they are not applying the strategies correctly, thus not reaping the benefits it can have on projects. Literature repeatedly tells us that value management is slowly moving from profitability to adding value to the end user [14,19,35], but this is evidently not happening in real-life situations and the Construction Leadership Council have also identified this as a huge problem. Value management would be advanced through the use of innovative technologies, governance, policies, and best practices. However, there are still so many issues surrounding the subject that need rectifying for the industry to proceed. One of the major steps that would enable delivery of value management in projects is holistic sustainability, which goes beyond economic considerations to also take into account environmental and social considerations. Environmental considerations can be incorporated through selecting sustainable materials, design decisions, and energy efficient systems [75]. The social aspects, and reflecting on this study, can be achieved through incorporating facility managers' perspectives to understand end users' needs and requirements [76].

Stakeholder integration in the whole life cycle can fundamentally have a vital impact on the success of a value management strategy, as well as the size of the team to be able to brainstorm, delegate responsibilities, and discuss various ideas [34]. Referring back to the analysis, the participants indicated that key stakeholders such as facility managers can play a key role in providing the needs and requirements of building users. The participants strongly believed that applying value management is determined by the level of detail 
the client wants, but even for larger scope projects, they said clients are still unconcerned, consequently costing projects when changes are required. Collaboration within the industry is becoming a huge concept and even the NEC (New Engineering Contract) have released an alliancing contract which permits the client to have several partners that make key decisions [77], which could work well for performing value management as an early strategy. Furthermore, the respondents also spoke about how collaboration within NEC contracts is centred and alliancing models are being more frequently used within the industry, which promotes shared risk and reward, and collaboration is a fundamental part of value management.

The Construction Leadership Council (CLC) has provided the industry with a Roadmap to Recovery, which has created awareness for the industry and its needs to evolve into new sustainable techniques and technological strategies to improve the whole life cycle value of an asset. The three-step plan explores the ideas of reinventing the industry through collaboration and partnership to deliver better value, which will transform the industry post COVID-19, therefore providing better performing infrastructure and buildings and a more productive and profitable sector [18]. After the participants were asked about the Construction Leadership Councils' plan to re-invent the industry, a general consensus was that none of them were aware of it. Due to the lack of knowledge on the CLC's plan to re-invent the industry, governing bodies either need to be doing more to alert the industry regarding their plan, or the CLC need to be marketing themselves directly to UK firms to help the industry understand what they are trying to do. The plan by the CLC should be focussed on interacting with people within the industry, as having a PowerPoint online is evidently not enough exposure. As they are government-led, they need to be facilitating their plan and incorporating it into the RICS guidance of value management, as the guidance is evidently what most quantity surveyors are familiar with.

It can be stated that the CLC has proposed a plan that prioritises specific aspects of construction, the majority of which can be used in a value management strategy, such as building safety and quality of materials, net zero carbon, and innovation which is a fundamental aspect within value management [18]. The participants during the focus group session showed they have in-depth knowledge of value management as a costcutting solution and do not believe that digital technologies are a way of re-inventing the industry. However, they begin to explain how the education on technologies such as BIM is poor, thus better guidance, governance, and procedures on these technologies could help aid the CLC's plan. Therefore, it is essential to take initiatives such as CLC recovery plans as an opportunity to re-think about different decisions, and how they can be optimised using advanced technologies.

\subsection{Summary of Discussion}

It can be stated that value management is a cost-cutting tool used when prompted by the client or mainly by budget issues to the cost plan. Therefore, it is highly reactive strategy used by quantity surveyors in real-life situations. However, literature would have you believe that it is shifting from initial capital growth to adding value for the end user, which does not seem to be the case. COVID-19 has prompted that COVID features within fit out designs has excelled in the saleability of an asset; however, large scale changes have not been evident in practice. What it has prompted is the need for the industry to evolve and adapt to a post COVID-19 industry, as participants were unaware of the innovative strategies that value management can undertake. Thus, communication between government, governing bodies, and industry professionals needs to progress. The focus group represented no knowledge of the CLC's plan to re-invent the industry, thus the plan needs to take invasive action to promote their plan to governing bodies or directly to industry professionals. Furthermore, the plan offers a lot of insightful ideas and will allow professional to be creative and innovative, therefore allowing the industry to remain dynamic and resourceful. 


\section{Proposed Strategy}

There have been so many research papers, journals, and books surrounding value management and the key elements of the outcomes and processes but a clear process that should be followed in order to ensure value management in a project does not exist. Balancing different needs and requirements is a major key to drive a value management strategy that support the whole life cycle. Therefore, a four-dimension framework (see Figure 4) is proposed as a result of the findings from this study, which are governance and policies, industry best practice, innovation and technology, and sustainability. Adopting these dimensions for a value management strategy will promote innovation and collaboration and allow disciplines to evolve especially post COVID-19. Although some of these dimensions complement some of the existing work (e.g., [38,39]) on considerations toward value management, the strategy proposed in this study provides an overarching approach that supports a more tangible integration of value management across the whole life cycle.

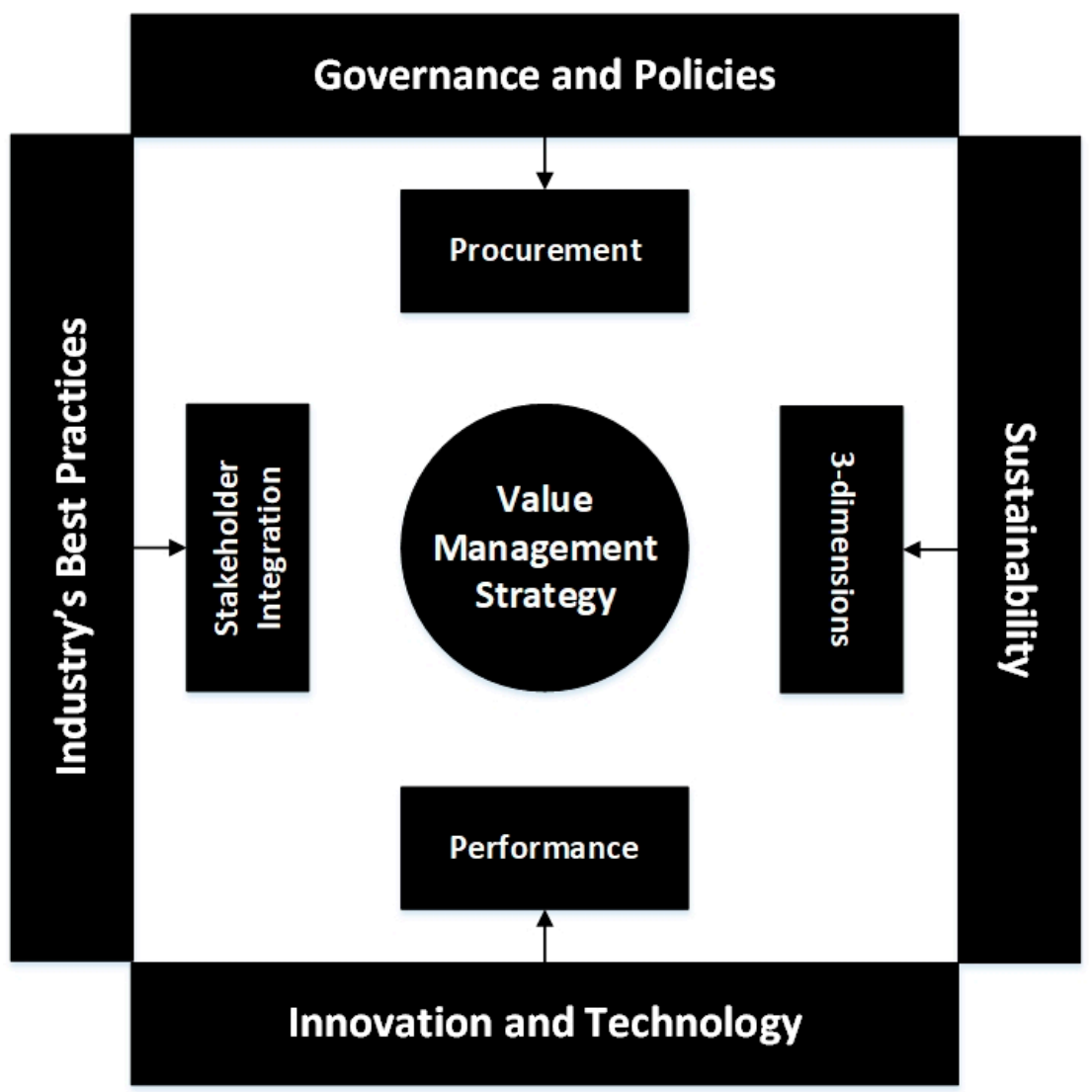

Figure 4. Four-dimension framework strategy for value management.

The main rationale behind each of the proposed dimensions is to allow more stakeholder integration, stress the importance of sustainable practices, and boost more opportunities to consider the value of applying innovative technologies, and position value management appropriately across different procurement routes. It is important to highlight that the synergy of these four dimensions would support maximising value management integration holistically which will be explained and reasoned in the below sections.

\subsection{Governance and Policies}

The first dimension, which is governance and policies for value management, is considered as one of the critical dimensions that impact the integration of value management across the whole life cycle. Governance has most notably been in the form of the RICS professional standard and guidance by David Churcher [35]. However, value management is evidently not being governed in the manner hoped and as resourcefully as hoped. Quan- 
tity surveyors refer to this document when prompted by the client or budget issues, but the industry needs to switch its focus from a reactive to proactive approach, therefore a value management strategy needs to be considered more tangibly during the procurement process. If the process can help cut costs post contract, then it can certainly help the project attain long term value pre contract, and without additional expense. It should be a legal obligation to apply value management, and this can be implemented by simply appointing a facility manager to utilise their innovative ideas on how to incorporate long-term value through building elements and focussing on a collaborative work environment, using digital technologies and modern ways of working. An obligation to implement a value management strategy pre contract could be imbedded into a project's approach; however, this approach could start with public sector projects only, similar to BIM level 2. Furthermore, the use of NEC contracts and alliancing in particular to utilise collaboration, which in turn will force clients to create an environment where digital technologies and industry best practices are naturally applied, thus value management being implemented.

Reflecting on professional bodies such as the RICS, there are currently over 134,000 qualified and trainee professionals across the built environment sector [78], therefore RICS should galvanise their value management procedures and guidance to involve the Construction Leadership Councils' plan. Therefore, a simple email sent to all members could show the dynamic changes and the processes that could help the industry progress into a post COVID phase. Along with the Construction Leadership Councils' Roadmap to Recovery, the Construction Innovation Hub released a value toolkit, which provides clients with a document that demonstrates how they can optimise the social, environmental, and economic outcomes for projects, get a deeper understanding of value in addition to the traditional cost, time, and quality, and provides up-to-date global best practices, which aligns with the national policy priorities set up in the Construction Playbook and Treasury's Green Book [79]. This is another concept that should be made mandatory for clients to complete in order to understand and utilise the benefits of a value management strategy [80].

\subsection{Industry Best Practices}

Applying best industry practice is completely client-dependent, regarding how much detail they want to incorporate into the project. Furthermore, the influence the client has on the success of a project, especially in the early stages is fundamental [81], therefore broader methods of working are required to achieve the clients' expectations. There are so many innovative ways to implement industry best practice and clients around the UK need to be better informed and start utilising these creative ways of working. The standards and best practices provided by governing bodies and the government have not progressed and productivity has fallen by half in the last 50 years as a result [82]. Best practices and value management can work in harmony and also bring an element of sustainability, which will considerably improve the efficiency of the industry. It is therefore essential that practices become more integrated and involve stakeholders who can provide value and the right level of input across the whole life cycle. For instance, embracing automation and standardisation through prefabrication, modularisation, and 3D printing will enhance quality by reducing errors and omissions, improve cost and productivity, and improve the environmental and sustainable aspects of construction projects significantly [83]. This also includes understanding how different stakeholders are integrated within many of the new processes (e.g., BIM) in order to expose more value and be able to inform design decisions more robustly [64].

The construction industry has seen a vast improvement in terms of best practices as a whole because of the communication and the ability to share new and innovative ideas that have worked in real-life situations [84]. Therefore, the same needs to be implemented for value management strategies that incorporates best practices, and a platform needs to be created to enable this. Although best practices within a value management strategy are fundamental for the industry to grow and improve, they are still being ignored consistently. 
However, if value management is made a legal obligation and is incorporated into the procurement of projects, then this could soon be a reality. The RICS guidance on value management is seen as a standard that provides best practice for the industry [39], but guidance should be more aligned to best practices through integrating key stakeholders who can inform critical decisions across the whole life cycle of a construction project.

\subsection{Innovation and Technology}

Technology can have a huge role to play in build quality of an asset, from manufacturing to installation, such as prefabrication, 3D printing, or modular construction, to name a few $[20,70]$. In addition, these technologies require great connectivity through the supply chain to the multi-disciplinary design team, which will help drive the use of technologies for future projects. However, including the right stakeholders during this process is fundamental. Another big technological breakthrough in terms of value management is the Internet of Things, which will redefine and unlock new forms of value. Reflecting on the importance of integration and how it plays an important aspect, during the focus group it was evident that the participants' knowledge of BIM was limited to technology offerings, but not how it can support driving more tangible recognition of value management. In fact, BIM in the private sector has been used in the context of 'lonely BIM', where big contractors are using it mainly for the construction phase instead of the whole lifecycle of a building, as they plan to sell or rent out the asset, thus not considering the operation and maintenance costs [85]. However, if value management was made a legal obligation, it could also encourage BIM to consider the whole life cycle of an asset and add a considerable amount of value. Although BIM is not necessarily a driver to value management, its ability to integrate different stakeholders can increase the understanding of a project's scope [15], whilst also making use of it within all stages of a project. The participants noted they have little knowledge on value management as an early strategy, but if it was made a legal obligation similar to BIM in the public sector, then the education of the process would have more latitude.

Beyond technologies that can support informing design and construction, there are other technologies that can boost more value management opportunities after building completion such as Internet of Things (IoT), which supports improving the efficiency, safety, and performance of building elements, in addition to creating a robust data and information collection system on a real-time basis for analysis [80] and perhaps reducing operational costs in the long term [86]. Such technologies can be seen as a great use of value management, which will be influential in reinventing the industry. The process from concept to design to construction, and to hand over to the client needs to be sharpened up and this can be done through value management at the earliest stages. Productivity is a major downfall of the industry and can be corrected by using collaborative strategies that engage personnel, machinery, and materials, which is focussed through the technologies discussed above [87]. Technology should also be the grounds on which to rationalise lean techniques such as module construction and 3D printing, as they minimise waste, and more importantly, support more sustainable choices, cost-effective solutions, and maintainable performance on the long-term.

\subsection{Sustainability}

Social, environmental, and economic are the three dimensions of sustainability within the construction industry and marrying these three aspects together will produce a sustainable project [88]. Sustainability is an unavoidable part of value management and is a subject that everybody in the industry should respect, as the future of the industry highly depends on being sustainable. There are concepts and accreditation schemes that can utilise sustainability to add considerable value for clients and end users.

Sustainability marries into best industry practices and requires innovation and technology to be implemented to its best ability, particularly within social needs and economic demand [89]. The industry needs to be looking at innovative concepts to help improve 
the sustainability of buildings while also improving the profitability, which the lean construction philosophy has created [90-92]. The concept includes a focus on the end user, eliminating waste resulting in higher profits, continuous improvement, and standardisation which coincides with industry best practices [24]. All of these aspects feed into the role of a value management strategy and where sustainability is at the forefront of the project, which is implemented using innovative digital technologies and is critical to the future of the industry.

Clients implementing techniques and methods to their assets for accreditations, such as BREEAM and WELL, is a good start, but they need to change their focus from profit and saleability to sustainability for the end user, which could be implemented by government funding. The government could fund a piece of the project to allow clients to reach these accreditations, but they need to make value management as an early strategy a requirement to promote collaborative working and digital technologies, and in turn a sustainable asset. A facility manager working in a collaborative environment, whilst including digital technologies and a zero-carbon approach could lead the industry to reinvigorate itself into one of the most dynamic and resourceful industries post COVID-19. Value management should have a stage of the project (pre contract), which should involve discussions on the three dimensions of sustainability and the implementation of lean construction.

\section{Conclusions}

Extant literature was reviewed and it became clear that value management was attempting to be applied, but in reality, it was being used as a cost-cutting tool, and thus not being applied effectively from the early stages of a project. The reviewed literature also identified critical challenges the UK will be facing, such as value management being highly client-dependent and a lack of knowledge within the processes. Consequently, further examination was required. A focus group was utilised to discover the key problem domains within the industry, which prompted an analysis that in turn prompted three key discussion points. The focus group, analysis, and discussion revealed that the process of value management needs to be centred at the early stages of a project instead of being client-dependent and used as a reactive process. Stakeholders within projects can have a lot of influence on how much value management is implemented, but if the process is an obligation within procurement, then a minimum amount of consideration has to be applied. Governance for value management does not exist yet, therefore it is essential for the government to act and make it a legal obligation. Industry best practice is centred on the client and the level of detail they want to apply, but this should be mandatory. Industry best practices are embedded within a value management strategy, therefore these innovative methods of working need to be incorporated into construction projects. The CLC's Roadmap to Recovery is complimentary to the industry and as a result is certainly not being utilised. Thus, the CLC needs to integrate the approach into the RICS professional standards and guidance, as this is the primary document that industry professionals are evidently aware of. Subsequent to the analysis and discussion, this study provides a framework to help improve the implementation of value management and the benefits it can award industry professionals. Industry best practices, innovation and technology, and sustainability are three pillars that all interlink with one another, and the concepts that are embedded within them need to be an early consideration to improve the quality, performance, and sustainability for the end user. It is important to note that, although the strategy proposed in this study was not validated, it supports shedding light on the dimensions that support more tangible integration of value management in projects. More importantly, validating the proposed strategy requires contextualisation within a real project scenario so that the role that each of these dimensions play can be explained more comprehensively with respect to different phases within a project. Therefore, future work should look into validating the framework resulting from this research through examining how it impacts different decisions across the whole life cycle so that it recognises value 
management more holistically. This should also take into account public and private clients to identify best strategies in defining value management in a project.

Author Contributions: Conceptualization, K.B. and M.M.; methodology, K.B.; validation, M.M.; formal analysis, M.M.; investigation, K.B.; resources, K.B.; writing-original draft preparation, K.B.; writing-review and editing, M.M.; supervision, M.M.; All authors have read and agreed to the published version of the manuscript.

Funding: This research received no external funding.

Institutional Review Board Statement: Not applicable.

Informed Consent Statement: Informed consent was obtained from all subjects involved in the study.

Data Availability Statement: The datasets used and/or analyzed during the current study are available from the corresponding author on reasonable request.

Conflicts of Interest: The authors declare no conflict of interest.

\section{References}

1. Kelly, J.; Male, S.; Graham, D. Value Management of Construction Projects, 2nd ed.; John Wiley \& Sons: Hoboken, NJ, USA, 2014.

2. Atabay, S.; Galipogullari, N. Application of Value Engineering in Construction Projects. J. Traffic Transp. Eng. 2016, 6, 25-29. [CrossRef]

3. Jaapar, A.; Endut, I.R.; Bari, N.A.A.; Takim, R. The Impact of Value Management Implementation in Malaysia. J. Sustain. Dev. 2009, 2, 210. [CrossRef]

4. Rangelova, F.; Traykova, M. Value Management in Construction Project. In Proceedings of the first Scientific Applied Conference with International Participation "Project Management in Construction", Sofia, Bulgaria, 4-5 December 2014; pp. 429-434.

5. Othman, I.; Kineber, A.; Oke, A.; Zayed, T.; Buniya, M. Barriers of value management implementation for building projects in Egyptian construction industry. Ain Shams Eng. J. 2020, 12, 21-30. [CrossRef]

6. Michalski, G. Corporate inventory management with value maximization in view. Czech Acad. Agric. Sci. 2008, 54, 187-192. [CrossRef]

7. Kishk, M.; Al-Hajj, A.; Pollock, R.; Aouad, G.; Bakis, N.; Sun, M. Whole life costing in construction: A state of the art review. RICS Found. Res. Pap. 2003, 4, 1-39.

8. Chakravarthy, P.R.; Janani, R.; Raj, R.R. A Study on Value Engineering \& Green Building in Residential Construction Value Engineering. Int. J. Civil Eng. Technol. 2018, 9, 900-907.

9. Opoku, A. The Application of Whole Life Costing in the UK Construction Industry: Benefits and Barriers. Int. J. Arch. Eng. Constr. 2013, 2, 35-42. [CrossRef]

10. Flanagan, R.; Jewell, C. A Practical Approach to Whole Life Appraisal for Construction. In Whole Life Appraisal for Construction; Blackwell Publishing: Oxford, UK, 2008; pp. 129-148.

11. Jones, W.; Chow, V.; Gibb, A. COVID-19 and Construction: Early Lessons for a New Normal? 2020. Available online: https: //www.balfourbeatty.com/media/318555/covid19-and-construction-early-lessons-for-a-new-normal.pdf (accessed on 29 June 2021).

12. Gallagher, S. The Lean-led Recovery from COVID-19: Four Steps to Improve Productivity. 2021. Available online: https://www. turnerandtownsend.com/en/perspectives/the-lean-led-recovery-from-covid-19-four-steps-to-improve-productivity/ (accessed on 29 June 2021).

13. Oyedolapo, O.; Oladapo, A.; Goulding, J. Innovative value management: Assessment of lean construction implementation. RICS Constr. Prop. Conf. 2011, 9, 696.

14. Leung, M.-Y.; Liu, A.M.M. Analysis of value and project goal specificity in value management. Constr. Manag. Econ. 2003, 21, 11-19. [CrossRef]

15. Wandahl, S. Practitioners' perception of value in construction. J. Civ. Eng. Manag. 2015, 21, 1027-1035. [CrossRef]

16. Edwards, D.J.; Pärn, E.A.; Love, P.E.D.; El-Gohary, H. Machinery, manumission, and economic machinations. J. Bus. Res. 2017, 70, 391-394. [CrossRef]

17. Eastman, C.; Teicholz, P.; Sacks, R.; Liston, K. BIM Handbook: A Guide to Building Information Modelling for Owners, Managers, Designers, Engineers, and Contractors; Wiley: Hoboken, NJ, USA, 2011.

18. Punnyasoma, J.; Jayasena, H.; Tennakoon, T. Use of BIM Solution to Facilitate Value Management. In Proceedings of the 8th World Construction Symposium, Colombo, Sri Lanka, 8-10 November 2019.

19. Parn, E.; Edwards, D.; Sing, M.C. Origins and probabilities of MEP and structural design clashes within a federated BIM model. Autom. Constr. 2018, 85, 209-219. [CrossRef] 
20. Construction Leadership Council. Roadmap to Recovery an Industry Recovery: Plan for the UK Construction Sector. 2020. Available online: https:/ /www.constructionleadershipcouncil.co.uk/wp-content/uploads/2020/06/CLC-Roadmap-to-Recovery01.06.20.pdf (accessed on 20 October 2020).

21. RICS. Value Management and Value Engineering. 2017. Available online: https://www.rics.org/globalassets/ricswebsite/media/upholding-professional-standards/sector-standards/construction/black-book/value-management-andvalue-engineering-1st-edition-rics.pdf (accessed on 29 June 2021).

22. Lateef, A.; Iskandar, B.S.; Ridzuan, P.D. A Critical Review of Value Management and Whole Life Costing on Construction Projects. 2013. Available online: https:/ / www.fmlink.com/articles/a-critical-view-of-value-management-and-whole-life-costing-onconstruction-projects / (accessed on 23 October 2020).

23. Bourke, K. Achieving Whole Life Value in Infrastructure and Buildings; BRE Bookshop: Watford, UK, 2015.

24. Tzanakakis, K. LLC and WLC (Whole Life Costing). In The Railway Track and Its Long Term Behaviour: A Handbook for a Railway Track of High Quality; Roess, R.P., Ed.; Springer: Berlin/Heidelberg, Germany, 2013; pp. 305-306.

25. Evans, R.; Haryott, R.; Haste, N.; Jones, A. The Long Term Costs of Owning and Using Buildings; Royal Academy of Engineering: London, UK, 1998.

26. Hughes, W.P.; Ancell, D.; Gruneberg, S.; Hirst, L. Exposing the Myth of the 1:5:200 Ratio Relating Initial Cost, Maintenance and Staffing Costs of office Buildings. In Proceedings of the 20th Annual ARCOM Conference, Edinburgh, UK, 1-3 September 2004; pp. 373-381.

27. Latham, M. Constructing the Team. 1994. Available online: https://constructingexcellence.org.uk/wp-content/uploads/2014/1 0/Constructing-the-team-The-Latham-Report.pdf (accessed on 2 November 2020).

28. Egan, J. Rethinking Construction-Construction Task Forces Report. 1998. Available online: https:/ / constructingexcellence.org. uk/wp-content/uploads/2014/10/rethinking_construction_report.pdf (accessed on 30 October 2020).

29. Wong, I. Whole Life Costing: Towards a Sustainable Built Environment. In Proceedings of the 5th International Conference on Responsive Manu-facturing-Green Manufacturing (ICRM 2010), Ningbo, China, 11-13 January 2010.

30. Perera, O. Life Cycle Costing: A Question of Value. 2009. Available online: https://ec.europa.eu/environment/gpp/pdf/WPLifeCycleCosting.qx.pdf (accessed on 17 October 2020).

31. Hutchins, G. Why It Pays to Get the Whole-Cost Picture at The Start of A Project-Modern Building Services. 2005. Available online: https:/ / modbs.co.uk/news/fullstory.php/aid/986/ (accessed on 19 November 2020).

32. Clift, M.; Bourke, K. Study of Whole Life Costing; BRE Press: London, UK, 2005.

33. Bull, J. Life Cycle Costing for Construction; Blackie Academic and Professional: London, UK, 2003.

34. El-Haram, M.A.; Marenjak, S.; Horner, M.W. Development of a generic framework for collecting whole life cost data for the building industry. J. Qual. Maint. Eng. 2002, 8, 144-151. [CrossRef]

35. Cheah, C.Y.; Ting, S.K. Appraisal of value engineering in construction in Southeast Asia. Int. J. Proj. Manag. 2005, 23, 151-158. [CrossRef]

36. Bruce-Hyrkäs, T.; Pasanen, P.; Castro, R. Overview of Whole Building Life-Cycle Assessment for Green Building Certification and Eco design through Industry Surveys and Interviews. Procedia CIRP 2018, 69, 178-183. [CrossRef]

37. Roufechaei, K.M.; Hassan, A.; Bakar, A. Value Management and Client Attitude in Developing Sustainable Construction. Adv. Environ. Biol. 2015, 9, 4-6.

38. Kelly, J.; Morledge, R.; Wilkinson, S. Best Value in Construction; Blackwell Publishing Ltd.: Hoboken, NJ, USA, 2002.

39. Oke, A.; Aigbavboa, C. Sustainable Value Management for Construction Projects; Springer: Berlin/Heidelberg, Germany, 2017.

40. Lehman, T.; Reiser, P. Maximizing Value and Minimize Waste: Value Engineering \& Lean Construction. Lean Constr. Inst. 2000, 1, $1-10$.

41. Nitin, L.; Rane, P. Application of Value Engineering in Commercial Building Projects. Int.J. Latest Trends Eng. Technol. 2016, 6, 286-291.

42. Ramya, G. Overcoming the Impact of COVID-19 Using Integrated Project Delivery Model. Res. Square 2020, 1, 1-14.

43. Ekanayake, E.; Sandanayake, Y. LiVE approach: Lean integrated Value Engineering for construction industry. Built Environ. Proj. Asset Manag. 2017, 7, 518-533. [CrossRef]

44. RICS. Pathway Guide: Quantity Surveying and Construction. 2018. Available online: https://www.rics.org/globalassets/ricswebsite/media/qualify / pathway-guides / quantity-surveying-construction-pathway-guide-chartered-rics.pdf (accessed on 27 November 2020).

45. Booth, J. Value Engineering in Modular Construction. 2019. Available online: https://www.pbctoday.co.uk/news/mmc-news/ engineering-modular-construction/56171/ (accessed on 5 December 2020).

46. Constructing Excellence. Value Management. 2004. Available online: https://constructingexcellence.org.uk/wp-content/ uploads/2015/03/value.pdf (accessed on 1 December 2020).

47. Thurston Group. Modular Buildings UK: The Rise to Prominence-Prefabricated Buildings—Modular Buildings—Portable Buildings Solutions. 2020. Available online: https:/ / www.thurstongroup.co.uk/blog/modular-buildings-uk-the-rise-to-prominence/ (accessed on 16 November 2020).

48. Hyams, A.; McCann, E.; Ferguson, H. Construction Methods: Modular. 2018. Available online: https://www.buildoffsite.com/ content/uploads/2018/07/Unlocking-the-Potential-of-Modular-Construction_Building-FINAL-by-Anilea.pdf (accessed on 16 November 2020). 
49. Modular Building Institute. What Is Modular Construction? Modular Building Institute. 2018. Available online: https: / / www.modular.org/HtmlPage.aspx?name=why_modular (accessed on 16 November 2020).

50. Actavo. 4 Reasons Why Modular Is More Sustainable Than Traditional Construction-Actavo. 2020. Available online: https:// actavo.com/latest-news/4-reasons-why-modular-is-more-sustainable-than-traditional-construction/ (accessed on 17 November 2020).

51. Aecom. Cost Model: Modular Construction. 2017. Available online: https://www.aecom.com/without-limits/wp (accessed on 4 January 2021).

52. Lawson, R.M.; Ogden, R.G. Sustainability and Process Benefits of Modular Construction. CIB Work. Pap. 2014, 38-51. Available online: http://site.cibworld.nl/dl/publications/tg57_pub354.pdf\#page=43 (accessed on 12 August 2021).

53. Social Housing. The Grenfell Inquiry and the Focus on 'Value Engineering'. 2020. Available online: https:/ /www.socialhousing. co.uk/insight/insight/the-grenfell-inquiry-and-the-focus-on-value-engineering-65299 (accessed on 10 October 2020).

54. Aghimien, D.O.; Oke, A.E.; Aigbavboa, C.O. Barriers to the adoption of value management in developing countries. Eng. Constr. Arch. Manag. 2018, 25, 818-834. [CrossRef]

55. Kelly, J.; Male, S. Value Management in Design and Construction; Routledge: London, UK, 2003.

56. Ellis, R.C.T.; Gerard, D.W.; David, A.K. Value management practices of leading UK cost consultants. Constr. Manag. Econ. 2005, 23, 483-493. [CrossRef]

57. Norton, B.R.; Mcelligott, W.C. Value Management in Construction: A Practical Guide; Springer: Berlin/Heidelberg, Germany, 1995.

58. Perera, S.; Hayles, C.; Kerlin, S. An analysis of value management in practice: The case of Northern Ireland's construction industry. J. Financ. Manag. Constr. 2011, 16, 94-110. [CrossRef]

59. Rhodes, C. The Construction Industry: Statistics and Policy. House of Commons Library. 2019. Available online: https: / / commonslibrary.parliament.uk/research-briefings/sn01432/ (accessed on 12 November 2020).

60. Construction Online. The Impact of COVID-19 Across the Construction Industry [Infographic]—Constructionline. 2020. Available online: https: / / www.constructionline.co.uk/insights/news/covid-19-infographic/ (accessed on 26 November 2020).

61. Office for National Statistics. Coronavirus and the Impact on Output in The UK Economy-Office for National Statistics. 2020. Available online: https:/ / www.ons.gov.uk/economy/grossdomesticproductgdp/articles/coronavirusandtheimpactonoutputintheukecon august2020\#construction (accessed on 15 November 2020).

62. Hammarberg, K.; Kirkman, M.; De Lacey, S. Qualitative research methods: When to use them and how to judge them. Hum. Reprod. 2016, 31, 498-501. [CrossRef] [PubMed]

63. Mayouf, M.; Gerges, M.; Cox, S. 5D BIM: An investigation into the integration of quantity surveyors within the BIM process. J. Eng. Des. Technol. 2019, 17, 537-553. [CrossRef]

64. Braun, V.; Clarke, V. Using thematic analysis in psychology. Qual. Res. Psychol. 2016, 3, 77-101. [CrossRef]

65. Wilberg, J.; Maisenbacher, S.; Lindemann, U. Proactive Cost Management: Integrating Use Phase Data to Reduce Uncertainty; NordDesign: Trondheim, Norway, 2016; pp. 1-10.

66. Taherdoost, H. Sampling Methods in Research Methodology; How to Choose a Sampling Technique for Research. Int. J. Acad. Res. Manag. 2017, 5, 18-27. [CrossRef]

67. Nyumba, T.O.; Wilson, K.; Derrick, C.J.; Mukherjee, N. The use of focus group discussion methodology: Insights from two decades of application in conservation. Methods Ecol. Evol. 2018, 9, 20-32. [CrossRef]

68. Fisher, L.H.; Edwards, D.J.; Parn, E.; Aigbavboa, C. Building design for people with dementia: A case study of a UK care home. Facilities 2018, 36, 349-368. [CrossRef]

69. Skitmore, M.; Daddow, T. Value Management in Practice: An Interview Survey. Aust. J. Constr. Econ. Build. 2012, 4, 11-18.

70. CIOB. Digital Construction. 2015. Available online: https:/ /www.ciob.org/digitalconstruction?gclid=Cj0KCQjwpdqDBhCSARIsAEUJ0 hPVsV_Yz-PPE27erg8RDixUfuOYVpYj_z8_fk1GLhoKKyHb1SSJ-EYaAhv1EALw_wcB (accessed on 14 April 2021).

71. Carling, L. Before and after of Office Designs during COVID. 2020. Available online: https:/ /diamondinteriors.co.uk/latestnews/office-designs-during-covid/ (accessed on 14 April 2021).

72. Jay, C.; Bowen, P. Value management and innovation: A historical perspective and review of the evidence. J. Eng. Des. Technol. 2015, 13, 123-143.

73. Connaughton, J.; Green, S. Value Management in Construction: A Client's Guide; Construction Industry Research and Information Association: London, UK, 1996.

74. Rahman, S.H.A.; Endut, I.R.; Faisol, N.; Paydar, S. The Importance of Collaboration in Construction Industry from Contractors' Perspectives. Procedia Soc. Behav. Sci. 2014, 129, 414-421. [CrossRef]

75. Rachwan, R.; Abotaleb, I.; Elgazouli, M. The Influence of Value Engineering and Sustainability Considerations on the Project Value. Procedia Environ. Sci. 2016, 34, 431-438. [CrossRef]

76. Mayouf, M.; Cox, S.; Boyd, D. Using Soft Systems to Explore the Complexity of Space beyond Digital Representations; CONVR: Banff, AB, Canada, 2015.

77. Oke, A. Value Management of Construction Projects: Strategic Option for Nigerian Quantity Surveyors. In Proceedings of the 2015 Annual Conference of Registered Quantity Surveyors, Abuja, Nigeria, 1-3 September 2015; pp. 1-8.

78. CMS. CMS Guide to Building Information Modelling (BIM). 2017. Available online: https://cms.law/en/int/expert-guides/ cms-expert-guide-to-building-information-modelling-bim (accessed on 16 April 2021). 
79. RICS. RICS Delivers Confidence through Respected Global Standards, Adopted and Enforced by Over 134,000 Qualified and TRAINEE professionals across the Built and Natural Environment. 2021. Available online: https://www.rics.org/uk/\#: \{\}: text=RICS\%20delivers\%20confidence\%20through\%20respected, the \%20built \%20and\%20natural\%20environment (accessed on 2 May 2021).

80. Oke, A.; Ogunsemi, D. Competencies of Quantity Surveyors as Value Managers in a Developing Economy. In Proceedings of the RICS COBRA Research Conference, Cape Town, South Africa, 10-11 September 2009; pp. 23-38.

81. Construction Innovation Hub. Value Toolkit. Driving Better Social, Environmental and Economic Outcomes through Value-Based Decision Making. 2021. Available online: https:/ / constructioninnovationhub.org.uk/value-toolkit/ (accessed on 3 May 2021).

82. Chigangacha, P.; Haupt, T. Effectiveness of client involvement in construction projects: A contractor perspective. In Proceedings of the ASOCSA 11th Built Environment Conference, Durban, South Africa, 6-8 August 2017; pp. 249-266.

83. Braddock, S. Report: Construction Productivity Fell by Half in Roughly the Last 50 Years. 2017. Available online: https: // constructioncitizen.com/blog/report-construction-productivity-fell-half-roughly-last-50-years/1708241 (accessed on 13 April 2021).

84. Construction Industry Institute. Industrial Modularization: How to Optimize; How to Maximize (Best Practice). 2015. Available online: https:/ / www.construction-institute.org/resources/knowledgebase/best-practices/planning-for-modularization/topics/ rt-283 (accessed on 21 April 2021).

85. Azmy, N.; Shane, J.S.; Strong, K. Adopting Construction Industry Institute (CII) Best Practices in Malaysia. In Proceedings of the AEC Conference, Port Arthur, TX, USA, 1-3 November 2010; pp. 1-9.

86. Bello, S.; Oyedele, L.; Akinade, O.; Bilal, M.; Delgado, M.; Akanbi, L.; Ajayi, A.; Owolabi, H. Cloud computing in construction industry: Use cases, benefits and challenges. Autom. Constr. 2020, 122, 103441. [CrossRef]

87. Yilmaz, M.; Bakis, A. Sustainability in Construction Sector. Procedia Soc. Behav. Sci. 2015, 195, 2253-2262. [CrossRef]

88. Constantinescu, A.; Frone, S. The Role of Technological Innovation in Sustainable Economic Development. Sci. Pap. Int. Conf. Knowl. Soc. 2014, 4, 1-13.

89. Dulaimi, M.; Tanamas, C. The Principles and Applications of Lean Construction in Singapore. In Proceedings of the 9th International Group for Lean Construction, Singapore, 6-8 August 2001; pp. 1-14.

90. Bajjou, M.S.; Chafi, A. The potential effectiveness of lean construction principles in reducing construction process waste: An input-output model. J. Mech. Eng. Sci. 2018, 12, 4141-4160. [CrossRef]

91. Fulford, R.; Standing, C. Construction industry productivity and the potential for collaborative practice. Int. J. Proj. Manag. 2014, 32, 315-326. [CrossRef]

92. Gamil, Y.; Abdullah, M.; Rahman, I.A.; Asad, M.M. Internet of things in construction industry revolution 4.0. J. Eng. Des. Technol. 2020, 18, 164. [CrossRef] 